\title{
VISCOMETRIC BEHAVIOR OF CONCENTRTED PERCHLORIC ACID
}

\author{
RENU LOSHALI and NARAIN DATT KANDPAL*
}

Physical Chemistry Laboratory, Department of Chemistry, Kumaun University, S. S. J. Campus, Almora 263601, Uttarakhand, India

\section{ABSTRACT}

Viscosity $\eta$ and density $\rho$ of aqueous concentrated perchloric acid $1.0 \mathrm{moldm}^{-3}$ to $9.0 \mathrm{moldm}^{-3}$ were measured at $297.65 \mathrm{~K}$. The viscosity data were used to calculate the value of A and B- coefficient of Jones- Dole equation. The value of B- coefficient is positive which suggests the strong ion- solvent interaction in aqueous perchloric acid. The three concentration regions of perchloric acid having value of B-coefficient (measure of ion-solvent interaction or structure making capacity) in the order 1.0 to $4.0 \mathrm{moldm}^{-3}<4.0$ to $6.0 \mathrm{moldm}^{-3}<6.0$ to $9.0 \mathrm{moldm}^{-3}$ has been proposed.

Keywords: Solution perchloric acid, viscosity equations, interaction parameters.

\section{INTRODUCTION}

The viscometric parameters in aqueous solution have been widely used to investigate the presence of solute- solute and solute-solvent interactions. There are number of reports on the properties of perchloric acid in detail using spectroscopic, analytical and physical methods ${ }^{1-6}$. The dependence of viscosity of aqueous perchloric acid and chemical shifts of NMR as a function of concentration has been reported ${ }^{7,8}$. In the study, it has been concluded that the ionization of perchloric acid takes place upto $6.0 \mathrm{moldm}^{-3}$ and above this the partially ionized forms are formed. The degree of ionization is uncertain at higher concentration region as also reported in literature ${ }^{6}$. The various hydrated species of perchloric acid in aqueous tributylphosphate has been reported ${ }^{9}$. For aqueous solution containing $\mathrm{ClO}_{4}^{-}$salts, $\mathrm{OH}$......ClO $\mathrm{Cl}_{4}$ absorption band of hydration shell of anion has been observed ${ }^{10}$. The hydrogen bonded network has been investigated in water and the influence of the acid on catalyzed reactions has also been reported ${ }^{11}$. The structural modification of water has been investigated conductometrically for perchlorates in methanol solution ${ }^{12}$ In aqueous solution the hydration studies have been reported ${ }^{13,14}$. In the present study the viscometric studies of aqueous concentrated perchloric acid have been undertaken in order to obtain interaction parameters.

\section{EXPERIMENTAL}

The perchloric acid was purchased from Qualigen and used without further purification. Doubly distilled water was used to prepare all concentrations of the acid. The strength of the each solution checked by titrating against a standard solution of sodium hydroxide using phenolphthalein as an indicator.

The viscosity measurements were performed in a calibrated suspendedlevel viscometer placed in a thermostated water bath for constant temperature of accuracy $\pm 0.1 \mathrm{~K}$. The solution of perchloric acid of known concentration was taken in the viscometer and the flow time of the solution was measured. Each measurement was repeated thrice and the average time of flow was used to calculate the viscosity. The viscometer used in the study was purchased from Infusil India Pvt. Ltd. having number BG43500 size 2 and BG43499 size 1. The densities of solutions were measured with calibrated pyknometer and single pan electronic balance (Citizen make).

\section{RESULTS AND DISCUSSION}

The different viscosity parameters for various viscosity models JonesDole, modified Jones-Dole, Grunberg-Nissan and Hind parameters have been calculated for concentrated perchloric acid in the concentration range 1.0 to $9.0 \mathrm{moldm}^{-3}$. The experimental viscosity and density data obtained in the study at $297.65 \mathrm{~K}$ are shown in Table 1 . The following equations were used for calculations

1. Jones-Dole equation: $\left(\mathrm{n} / \mathrm{n}_{0}-1\right) \mathrm{c}^{-0.5}=\mathrm{A}+\mathrm{B} \mathrm{c}^{0.5} \ldots \ldots$ (1.0) ..(2.0)

2. Modified Jones-Dole equation: $\left(n / n_{0}-1\right)\left(n_{s} / n_{w}\right)^{-0.5}=A_{x}+B_{x}\left(n_{s} / n_{w}\right)^{0.5}$

3. Grunberg- Nissan equation: $\ln \eta=x_{1} \ln \eta_{1}+x_{2} \ln \eta_{2}+x_{1} x_{2} d_{12}$

4. Hind equation: $\eta=x_{1}^{2} \eta_{1}+x_{2}^{2} \eta_{2}+2 x_{1} x_{2} H_{12} \ldots \ldots \ldots$ (4.0)

where $\eta$ is viscosity of solution, $\eta_{0}$ is viscosity of solvent, $A$ is a constant which is the measure of ion-ion interaction; $\mathrm{B}$ is constant which is the measure of ion-solvent interaction, $c$ is concentration of $\mathrm{HClO}_{4}, \mathrm{n}_{\mathrm{s}}$ is mole fraction of solute, $n_{w}$ is mole fraction of solvent, $\eta_{1}$ is viscosity of component $1, \eta_{2}$ viscosity of component $2, \mathrm{~d}_{12}$ is Grunberg-Nissan parameter and $\mathrm{H}_{12}$ is Hind parameter.

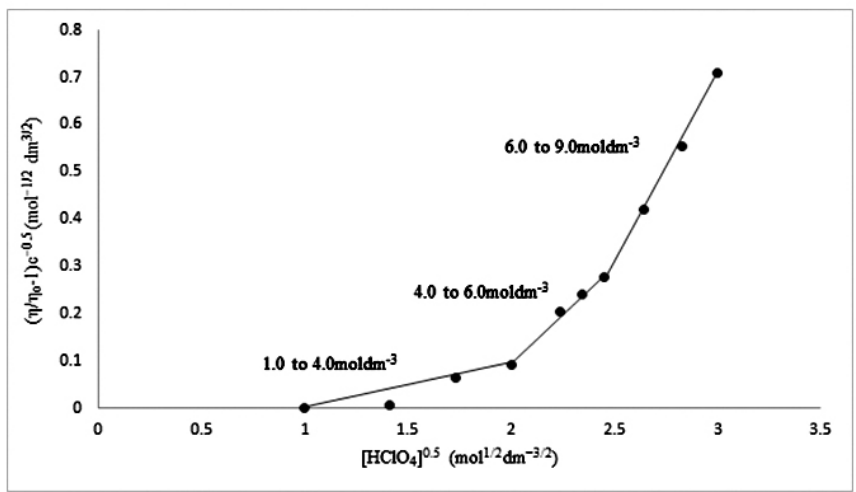

Figure 1. Jones-Dole plot for aqueous perchloric acid for different concentration at $297.65 \mathrm{~K}$.

The logarithmic relation between the viscosity of solution and pure component has been utilized to calculate the interaction parameter $d_{12}$ for whole concentration region. The B-coefficient have positive values which indicates high solute-solvent interaction ${ }^{15}$. The $\mathrm{d}_{12}$ values confirm the presence of three concentration region in Grunberg-Nissan plot ${ }^{16}$ and also indicates the relation between concentration and $\mathrm{H}_{12}$ parameter of Hind equation ${ }^{17}$ as shown in Figure 2. The interaction parameters calculated $\mathrm{d}_{12}, \mathrm{H}_{12}$ for each concentration are listed in Table 2.

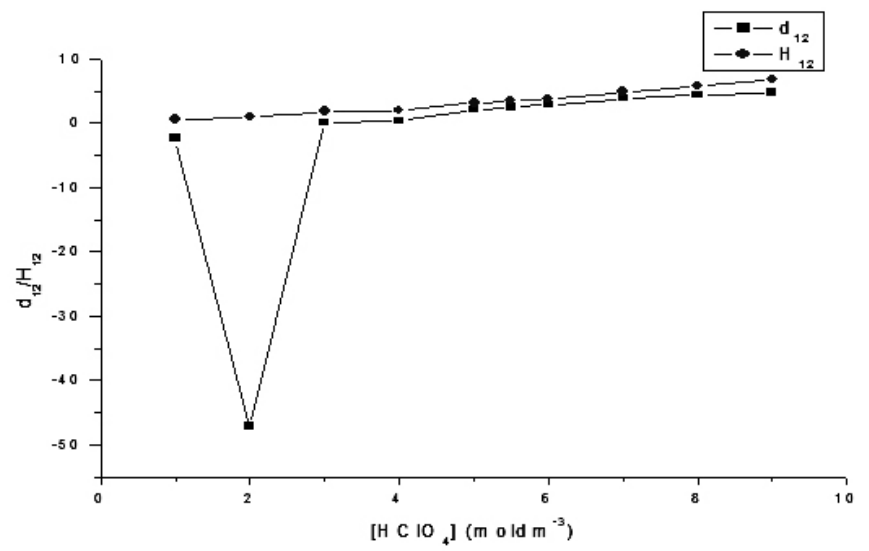

Figure 2. Grunberg -Nissan and Hind plot for perchloric acid (1) + water (2) system at $297.65 \mathrm{~K}$. 
Table 1. Variation of viscosity $(\eta)$ and density $(\rho)$ of aqueous perchloric acid with increasing concentration at $297.65 \mathrm{~K}$

\begin{tabular}{|c|c|c|c|c|c|c|c|}
\hline $\mathrm{c}\left(\mathrm{moldm}^{-3}\right)$ & $\eta(\mathrm{cP})$ & $\mathrm{c}^{0.5}\left(\mathrm{~mol}^{1 / 2} \mathrm{dm}^{-3 / 2}\right)$ & $\rho\left(\mathrm{gcm}^{-3}\right)$ & $\eta / \eta_{\mathrm{o}}$ & $\begin{array}{c}\left(\eta / \eta_{-}-1\right) \mathrm{c}^{-0.5} \\
\left(\mathrm{~mol}^{-1 / 2} \mathrm{dm}^{3 / 2}\right)\end{array}$ & $\begin{array}{c}\left(\mathrm{n}_{\mathrm{s}} / \mathrm{n}_{\mathrm{w}}\right)^{0.5} \\
\left(\eta / \eta_{\mathrm{o}}-1\right) /\left(\mathrm{n}_{\mathrm{s}} /\right. \\
\left.\mathrm{n}_{\mathrm{w}}\right)^{0.5}\end{array}$ \\
\hline 1.0 & 0.977 & 1.000 & 1.030 & 0.987 & -0.012 & 0.138 & -0.091 \\
\hline 2.0 & 0.998 & 1.414 & 1.091 & 1.008 & 0.005 & 0.200 & 0.041 \\
\hline 3.0 & 1.100 & 1.732 & 1.156 & 1.111 & 0.064 & 0.251 & 0.443 \\
\hline 4.0 & 1.170 & 2.000 & 1.202 & 1.182 & 0.091 & 0.299 & 0.607 \\
\hline 5.0 & 1.441 & 2.236 & 1.270 & 1.455 & 0.203 & 0.342 & 1.332 \\
\hline 5.5 & 1.550 & 2.345 & 1.310 & 1.565 & 0.241 & 0.361 & 1.566 \\
\hline 6.0 & 1.666 & 2.449 & 1.350 & 1.683 & 0.278 & 0.380 & 1.797 \\
\hline 7.0 & 2.093 & 2.645 & 1.408 & 2.114 & 0.421 & 0.422 & 2.638 \\
\hline 8.0 & 2.541 & 2.828 & 1.461 & 2.567 & 0.554 & 0.467 & 3.350 \\
\hline 9.0 & 3.093 & 3.000 & 1.517 & 3.124 & 0.708 & 0.513 & 4.133 \\
\hline
\end{tabular}

1.0 to 4.0 moldm $^{-3}\left(B=0.097 \mathrm{dm}^{-3 / 2} \mathrm{~mol}^{-1}, \mathbf{A}_{x}=-0.640 ; \mathbf{B}_{\mathrm{x}}=4.102\right) ; 4.0$ to $6.0 \mathbf{m o l d m}^{-3}\left(\mathrm{~B}=0.420 \mathrm{dm}^{-3 / 2} \mathrm{~mol}^{-1}, \mathbf{A}_{\mathrm{x}}=-3.847 ; \mathbf{B}_{\mathrm{x}}=14.95\right) ; \mathbf{6 . 0}$ to $9.0 \mathrm{moldm}^{-3}$ $\left(\mathrm{B}=0.773 \mathrm{dm}^{-3 / 2} \mathrm{~mol}^{-1}, \mathbf{A}_{\mathrm{x}}=-4.721 ; \mathbf{B}_{\mathrm{x}}=17.26\right)$

The values of $A$ and $B$ were obtained from the intercept and the slope of linear plot of $\left(\eta / \eta_{0}-1\right) c^{-0.5}$ versus $c^{0.5}$ as shown in Figure 1. The slope and intercept values are given at the bottom of Table 1 . The values of $A_{x}$ and $B_{x}$ were evaluated from the intercept and slope of the linear plot of $\left(n / n_{0}-1\right)\left(n_{s} / n_{w}\right)^{-0.5}$ versus $\left(n_{s} /\right.$ $\left.\mathrm{n}_{\mathrm{w}}\right)^{0.5}$. With the help of computer using regression analysis, the three concentration regions have been obtained from the graph.

Table 2. Values of $\mathrm{x}_{1}, \mathrm{x}_{2}, \mathrm{~d}_{12}, \mathrm{H}_{12}, \mathrm{E}^{*}$ and $\mathrm{k}_{\mathrm{obs}}$ for different concentration of perchloric acid (1) + water (2) system at $297.65 \mathrm{~K}$

\begin{tabular}{|c|c|c|c|c|c|}
\hline $\mathrm{c}\left(\mathrm{moldm}^{-3}\right)$ & $\mathrm{x}_{1}$ & $\mathrm{x}_{2}$ & $\mathrm{~d}_{12}$ & $\mathrm{H}_{12}(\mathrm{cP})$ & $\mathrm{E}^{*}(\mathrm{~kJ})$ \\
\hline 1.0 & 0.018 & 0.981 & -2.372 & 0.618 & -0.07 \\
\hline 2.0 & 0.038 & 0.961 & -47.185 & 1.022 & -0.02 \\
\hline 3.0 & 0.059 & 0.940 & 0.138 & 1.849 & 0.23 \\
\hline 4.0 & 0.082 & 0.917 & 0.411 & 1.998 & 0.36 \\
\hline 5.0 & 0.104 & 0.895 & 2.159 & 3.153 & 0.90 \\
\hline 5.5 & 0.115 & 0.884 & 2.525 & 3.462 & 1.08 \\
\hline 6.0 & 0.126 & 0.873 & 2.833 & 3.756 & 1.26 \\
\hline 7.0 & 0.151 & 0.848 & 3.883 & 4.913 & 1.82 \\
\hline 8.0 & 0.179 & 0.820 & 4.394 & 5.804 & 2.31 \\
\hline 9.0 & 0.208 & 0.791 & 4.810 & 6.806 & 2.79 \\
\hline
\end{tabular}

These results confirm the presence of three concentration regions 1.0 to 4.0 moldm $^{-3}, 4.0$ to 6.0 moldm $^{-3}$ and 6.0 to $9.0 \mathrm{moldm}^{-3}$ in the concentrated aqueous perchloric acid. The first two concentration regions can be explained on the basis of ion-solvent interaction and association as shown in the Scheme1 whereas at higher concentration, the structure $\mathrm{A}$ is responsible which form a hydrogen-bonded network in the concentrated perchloric acid where the presence of unionized or partially ionized perchlorate molecules have been concluded.
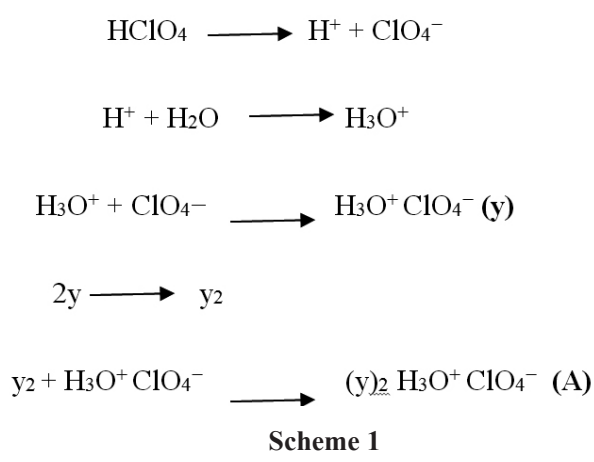

The various solute-solvent interaction of hydrochloric acid in water has been reported ${ }^{18}$. The free energy of activation of viscous flow has been calculated using Erying viscosity equation ${ }^{19}$.

$$
\eta=A e^{E^{*} / R T} \text {. }
$$

where $E^{*}$ is energy of activation of molecule for taking part in the flow of liquid. The flow depends upon the viscosity and temperature. The values of $\mathrm{E}^{*}$ are given in Table 2 for each concentration. The $\mathrm{E}^{*}$ value increases with concentration of acid which indicates the strong interaction between water and $\mathrm{HClO}_{4}$ molecule. These values also indicates the presence of associative type of structures in higher concentration range whereas in lower concentration region dissociation is possible as indicated by the slow increase of $\mathrm{E}^{*}$.

\section{CONCLUSIONS}

The viscometric data obtained from different equations has been utilized to analyze the interaction parameters which confirm the presence of three concentration regions in perchloric acid- water system with following order of B-coefficient (measure of ion-solvent interaction or structure making capacity): 1.0 to $4.0 \mathrm{moldm}^{-3}<4.0$ to $6.0 \mathrm{moldm}^{-3}<6.0$ to $9.0 \mathrm{moldm}^{-3}$. In concentration region 1.0 to 4.0 moldm $^{-3}$, the existence of $\mathrm{H}_{3} \mathrm{O}^{+}$(ion-solvent interaction) has been proposed. In concentration region 4.0 to $6.0 \mathrm{moldm}^{-3}$, intermolecular 
association is more effective due to the large number of bond formation between the solute and solvent molecules or association which leads to the formation of species, $\mathrm{H}_{3} \mathrm{O}^{+} \mathrm{ClO}_{4}^{-}$. In concentration region 6.0 to $9.0 \mathrm{moldm}^{-3}$, the solute- solvent interaction attains the higher value and intermolecular forces are completely effective due to the formation of hydrogen-bonded species like (y) $\mathrm{H}_{3} \mathrm{O}^{+} \mathrm{ClO}_{4}^{-}$. The increasing value of $\mathrm{E}^{*}$ with increasing concentration also confirm the strong interaction between water and $\mathrm{HClO}_{4}$ molecule. The kinetics data also supports the existence of three concentration regions in perchloric acid-water system. The study is an illustrative model to investigate the properties of a solvent for the particular reaction or industrial process and in the advancement of solution chemistry

\section{REFERENCES}

[1]. A. I. Karelin, Z. I. Grigorovich, V. Ya Rosolovskii, Spectrochim Acta A: Molecular spectroscopy 31, 765 (1975).

[2]. R. W. Duerst, J. Chem. Phys. 48, 2275 (1968).

[3]. L. H. Jones, R. A. Penneman, J. Chem. Phys. 21, 542 (1953).

[4]. P. S. Knapp, R. O. Waite, E. R. Malinowski, J. Chem. Phys. 49, 5459 (1968).

[5]. M. Leuchs, G. Zundel, J. Chem. Soc. Faraday Trans. 2 74, 2256 (1978).

[6]. J. W. Akitt, A. K. Covington, J. G. Freeman, T. H. Lilley, Trans. Faraday Soc. 65, 2701 (1969).

[7]. G. V. Lagodzinskaya, G. B. Manelis, Z. K. Nikitine, V. I. Shestov, V. Ya Rosolovskii, Russ. Chem. Bull. 34, 708 (1985).

[8]. A. I. Karelin, V. A. Tarasenko, Russ. Chem. Bull., Int. Ed. 52, 1959 (2003).
[9]. A. S. Kertes, V. Kertes, J. Appl. Chem. 10, 287 (1960).

[10]. H. J. Bakker, M. F. Kropmann, A. W. Omta, J. Phys.: Condens. Matter 17, S3215 (2005).

[11]. H. S. Harned, N. N. T. Samaras, J. Am. Chem. Soc. 54, 9 (1932).

[12]. N. H. El Hammamy, A. A. Hasanein, M. F. Amira, F. M. ABD El Halim, J. Indian Chem. Soc. LXI, 512 (1984).

[13]. A. D. Aprano, J. Phys. Chem. 75, 3290 (1971)

[14]. P. G. Traverso, Can. J. Chem. 62, 153 (1984).

[15]. E. R. Nightingale, B. E. Conway, R. G. Barradas, Chemical Physics of Ionic Solution, Wiley, New York, 1966.

[16]. L. Grunberg, A. H. Nissan, Nature 164, 799 (1949).

[17]. R. K. Hind, E. McLaughlin, A. R. Ubbelohde, Trans. Faraday Soc. 56, 328 (1960).

[18]. R. Loshali, B. Chandra, N. Sah, N. D. Kandpal, Int. J. Chem. Sci. 12, 1439 (2014).

[19]. H. Erying, M. S. John, Significant liquid structure, Wiley, New York, 1969.

\section{ACKNOWLEDGEMENT}

The authors are thankful to Prof. Raj N. Mehrotra, former Professor and Head, Chemistry Department, Jodhpur University and Prof. Lata Joshi, former Professor and Head, Chemistry Department, Kumaun University for useful help with valuable suggestions. 